\title{
FABRICATION AND TESTING OF ALUMINUM BASED
}

\section{COMPOSITE MATERIAL}

\section{P. NAGABHARAM, N. GOPIKRISHNA, L. RADHAKRISHNA \&}

\section{J. MANOJ KUMAR}

Assistant Professors, Department of Mechanical Engineering, S R Engineering College, Warangal, Telangana, India

Composite materials are becoming more important in the construction of aerospace structures. Aircraft parts made from composite materials, such as fairings, spoilers, and flight controls, were developed during the 1960s for their weight savings over aluminum parts. New generation large aircraft are designed with all-composite fuselage and wing structures and the repair of these advanced composite materials requires an in-depth knowledge of composite structures, materials, and tooling. The primary advantages of composite materials are their high strength, relatively low weight, and corrosion resistance.

Composite materials are generally used for buildings, bridges, and structures such as boat hulls, swimming pool panels, race car bodies, shower stalls, storage tanks, imitation granite and cultured marble sinks and countertops. The most advanced examples perform routinely on spacecraft and aircraft in demanding environments.

KEYWORDS: Hardness, Impact Test, Tension Test \& Composite Material
\end{abstract}

Received: Sep 15, 2018; Accepted: Oct 06, 2018; Published: Dec 13, 2018; Paper Id.: IJMPERDDEC2018075

\section{INTRODUCTION}

Composite materials made from two or more constituent materials with significantly different physical or chemical properties, that when combined, produce a material with characteristics different from the individual components. The individual components remain separate and distinct within the finished structure.

[1]. Revankar et. al., Introduced - Introduction to hardness testing." Mechanical testing and evaluation. [2] J. Manoj kumar and N. Gopikrishna et. al., made comparative studies on mechanical characteristics of granulated blast furnace slag and fly ash reinforced aluminum composites [3]. Czichos et. al., introduced - Handbook of Materials Measurement Methods. [4] Poursartip A et. al., Introduced - Instrumented Impact Testing at High Velocities, Journal of Composites Technology and Research [5] Toropov et. al., Dynamic Calibration of Impact Test Instruments, Journal of Testing and Evaluation. [6]. P. Nagabharam et al., fabricated and characterized Aluminum Based Composite Material and tested the specimens. [7]. Dieter et al., Introduced - Mechanical Metallurgy, which is useful for studying the metallurgical properties of the materials. [8] P. Nagabharam, L. Radhakrishna, and Dheeraj Joshi et. Al. investigated mechanical properties of aluminum based composite material.

\section{Classification of Composites}

- Metal Matrix Composite: Metal matrix composites are composed of a metallic matrix (aluminum, magnesium, iron, cobalt, copper) and a dispersed ceramic (oxides, carbides) or metallic (lead, tungsten, 
molybdenum) phase.

- Ceramic Matrix Composite: Ceramic matrix composites are composed of a ceramic matrix and embedded fibers of other ceramic material (dispersed phase).

- Polymer Matrix Composite: Polymer matrix composites are composed of a matrix from thermoset, Epoxy, Polyvinylchloride, Nylon, and embedded glass, carbon, steel or Kevlar fibers.

The composite made in this project is of metal-metal matrix composite type.

\section{EXPERIMENTATION}

The composite materials used in this study are:

\section{Aluminum}

The purpose of choosing aluminum as a material because of its features, Properties as shown below:

- $\quad$ Lightweight, strong and long-lasting:

- Highly corrosion resistant:

- Excellent heat and electricity conductor:

- Good reflective properties:

- Very ductile:

- Completely impermeable and odorless:

- Totally recyclable

\section{Copper}

Copper is a chemical element with symbol $\mathrm{Cu}$ and atomic number 29. A freshly exposed surface of pure copper has a reddish orange color. Copper is used as a conductor of heat and electricity, as a building material, and as a constituent of various metal alloys, such as Sterling silver used in jewelry, cupronickel used to make marine hardware and coins, and constantan used in strain gauges.

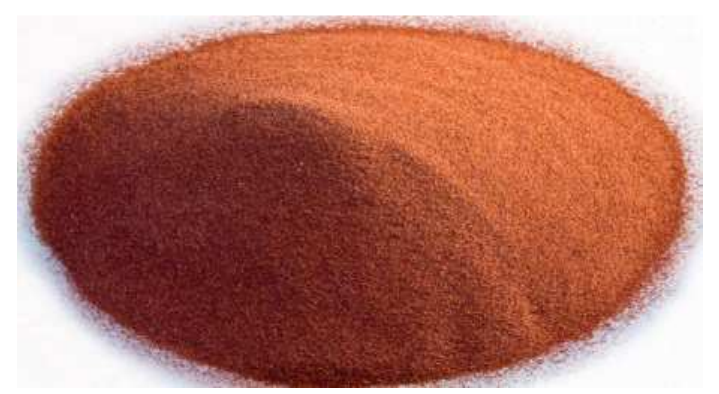

Figure 2: Copper

Copper is one of the few metals that occur in nature indirectly usable metallic form as opposed to needing extraction from an ore. This led to very early human use, from 8000 BC. It was the first metal to be smelted from its ore. 
The first metal to be cast into a shape in a mold and the first metal to be purposely alloyed with another metal, tin, to create bronze.

\section{Silicon Carbide}

Silicon carbide is the only chemical compound of carbon and silicon. It was originally produced by a hightemperature electrochemical reaction of sand and carbon.

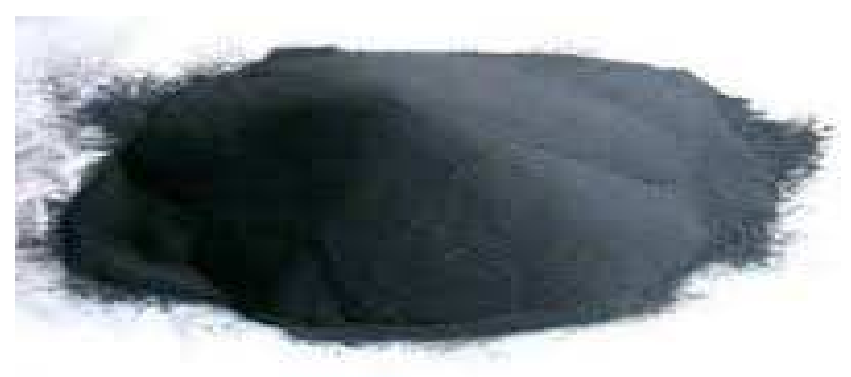

Figure 3: Silicon Carbide

Silicon carbide is an excellent abrasive and has been produced and made into grinding wheels and other abrasive products for over one hundred years. Today the material has been developed into a high-quality technical grade ceramic with very good mechanical properties. It is used in abrasives, refractoriness, ceramics, and numerous high-performance applications. The material can also be made an electrical conductor and has applications in resistance heating, flame igniters, and electronic components. Structural and wear applications are constantly developing.

- CASTING: Casting is a manufacturing process by which a liquid material is usually poured into a mold, which contains a hollow cavity of the desired shape, and then allowed to solidify. The solidified part is also known as a casting, which is ejected or broken out of the mold to complete the process. Casting materials are usually metals or various cold setting materials that cure after mixing two or more components together; examples are epoxy, concrete, plaster, and clay.

- STIR CASTING: The term stir casting is the process of stirring molten metals are used for continuous stirring particles into metal alloy to melt and immediately pour into the sand mold then cooled and allow to solidify. In stir casting, the particles often tend to form agglomerates, which can be only dissolved by vigorous stirring with high temperature.

Preparation Process: In the preparation process of this method, stirring has been carried out in a graphite crucible in coal-fired furnace with continuous stirring of the molten metal matrix gives the homogenous mixture of composites and instantaneously poured into the sand mold to get solidify. Coal is used as a fuel for preparation. The working diagram of the coal fired-furnace is given below. 


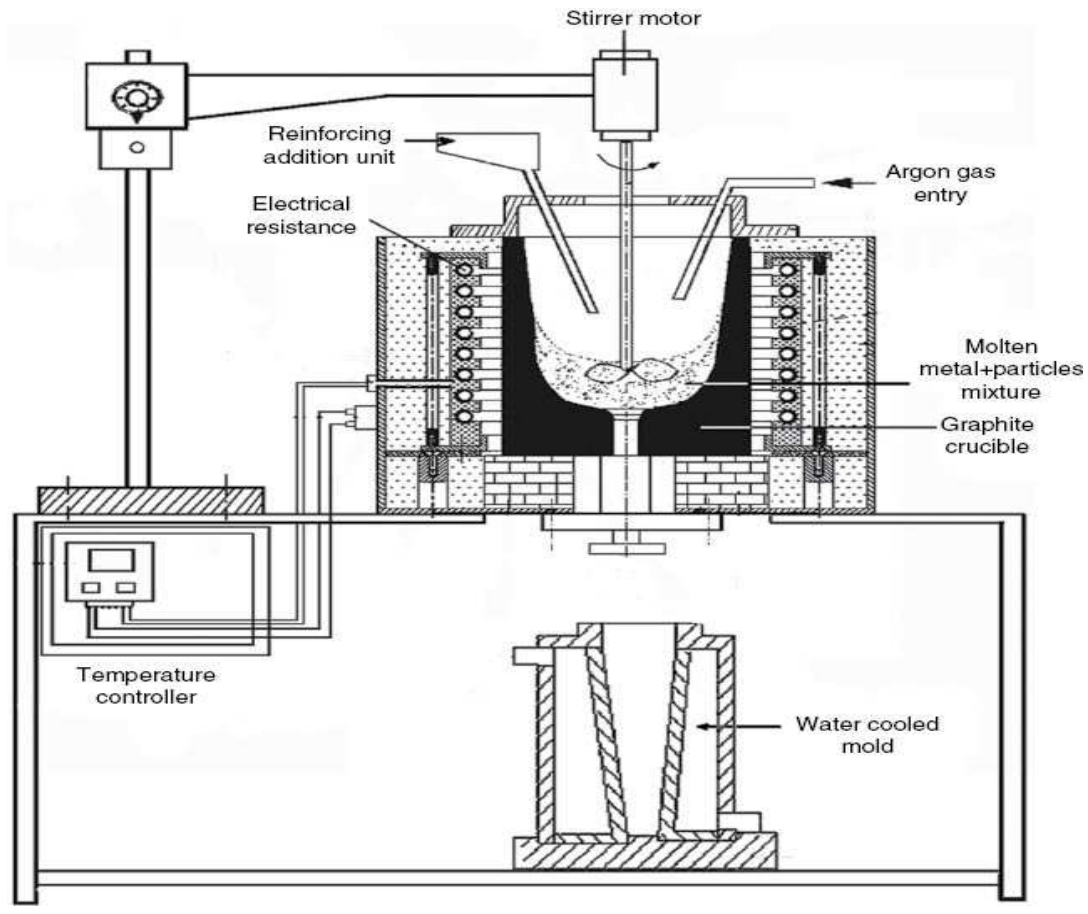

Figure 4: Stir Casting Equipment

\section{Fabrication of Composite Specimen}

Apparatus Required

- $\quad$ Cope and drag

- Pattern

- $\quad$ Stirrer

\section{Principle}

A mold is prepared as per the dimensions of the pattern and its geometric shape. Molten metal is then poured into the mold, it holds the material in shape as it solidifies and metal casting is created.

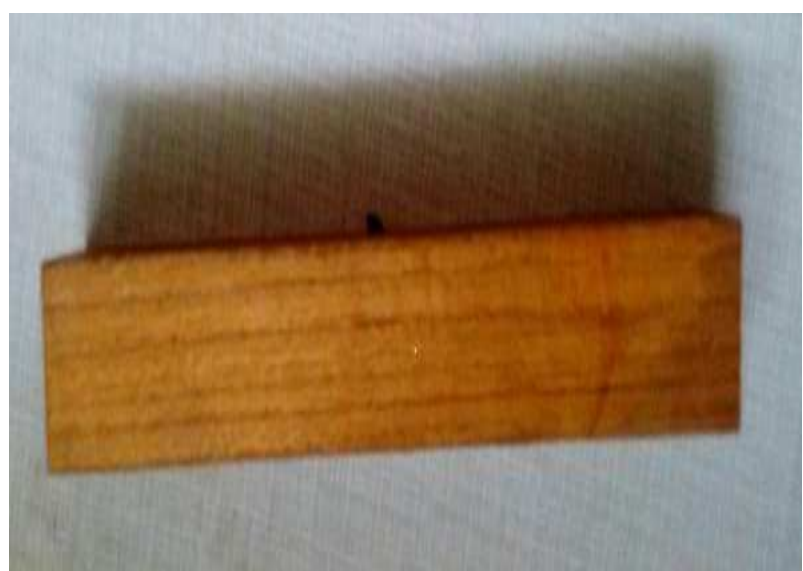

Figure 5: Wooden Pattern

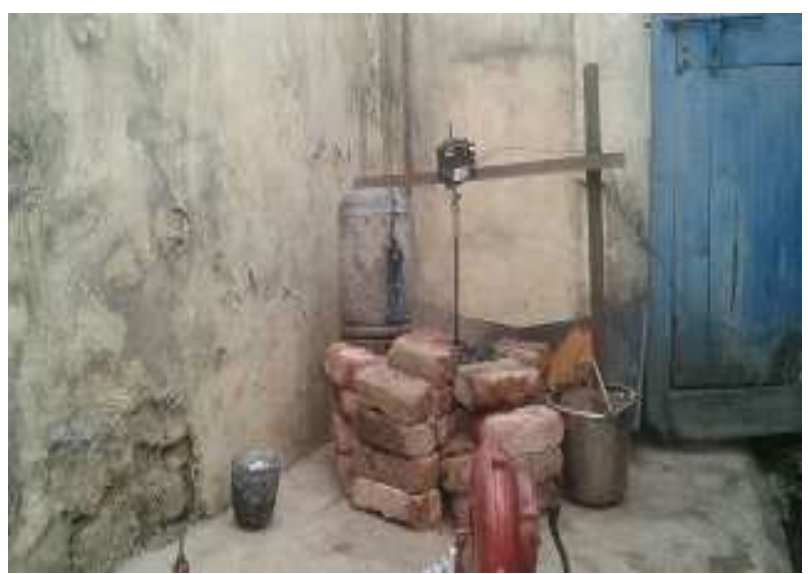

Figure 6: Setup for the Stir Casting Process 


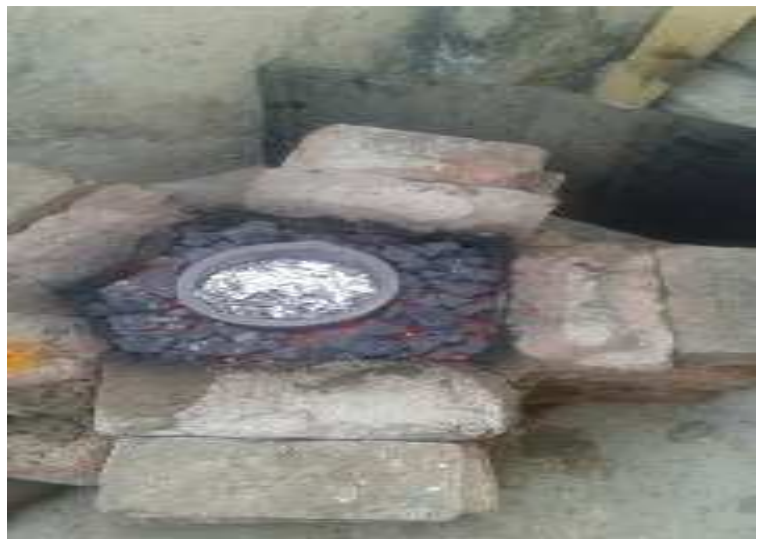

Figure 7: Molten Metals in Graphite Crucible

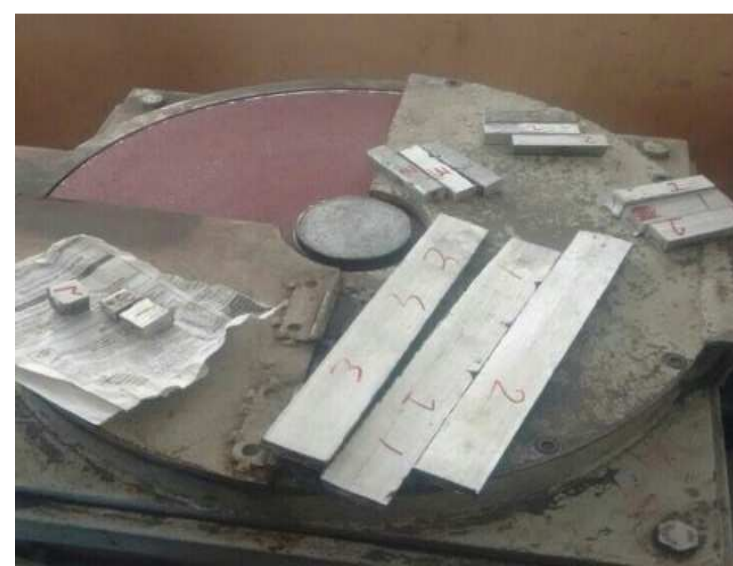

Figure 8: Composite Specimen after Casting and Cutting

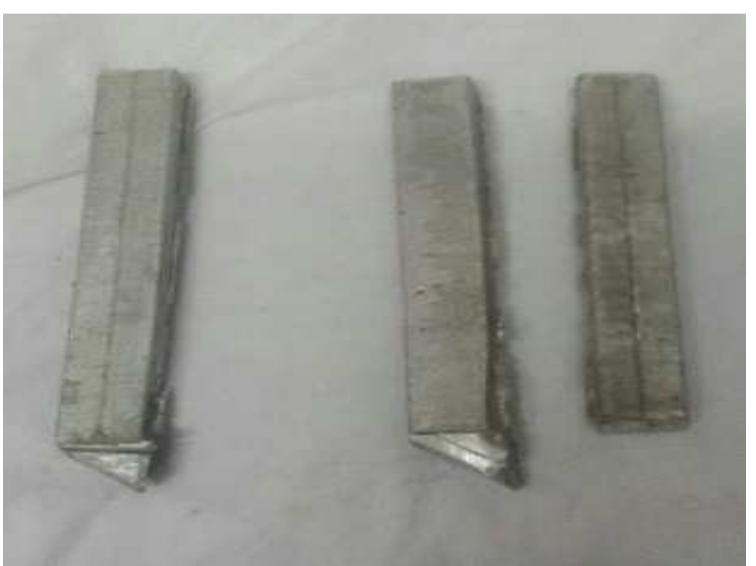

Figure 9: Composite Materials after Casting

\section{TESTS CARRIED OUT}

\section{Tension Test}

\section{Theory}

Tensile testing, also known as tension testing, is a fundamental material science test in which a sample is subjected to a controlled tension until failure. The results from the test are commonly used to select a material for an application, for quality control, and to predict how a material will react under other types of forces.

Properties that are directly measured via a tensile test are ultimate tensile strength, maximum elongation, and reduction in area. From these measurements, the following properties can also be determined: Young's modulus, Poisson's ratio, yield strength, and strain-hardening characteristics.

\section{Tensile Specimen}

A tensile specimen is a standardized sample cross-section. It has two shoulders and a gauge (section) in between. The shoulders are large so they can be readily gripped, whereas the gauge section has a smaller cross-section so that the deformation and failure can occur in this area.

The shoulders of the test specimen can be manufactured in various ways to mate to various grips in the testing machine (see the image below). Each system has advantages and disadvantages; for example, shoulders designed for serrated grips are easy and cheap to manufacture, but the alignment of the specimen is dependent on the skill of the 
technician. On the other hand, a pinned grip assures good alignment. Threaded shoulders and grips also assure good alignment, but the technician must know to thread each shoulder into the grip at least one diameter's length, otherwise, the threads can strip before the specimen fractures.

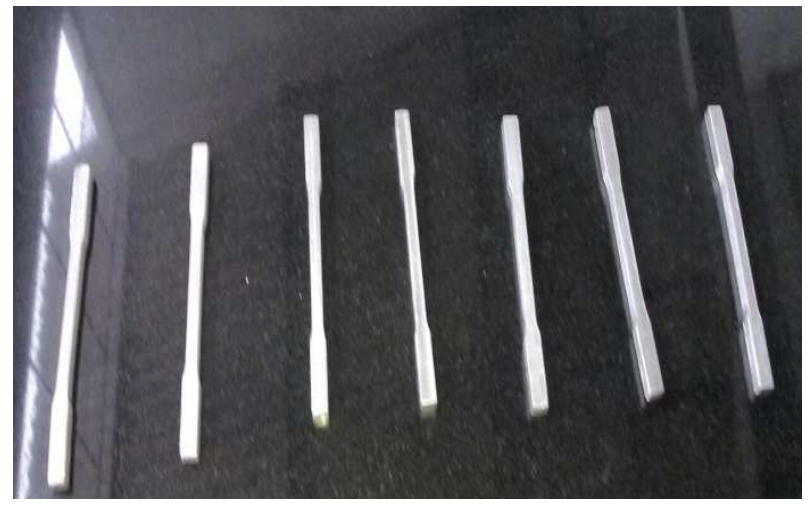

Figure 10: Tensile Specimens

EQUIPMENT: Universal Testing Machine The most common testing machine used in tensile testing is the universal testing machine. This type of machine has two crossheads; one is adjusted for the length of the specimen and the other is driven to apply tension to the test specimen. There are two types: hydraulic powered and electromagnetically powered machines.

The machine must have the proper capabilities for the test specimen being tested. There are four main parameters: force capacity, speed, and precision and accuracy. Force capacity refers to the fact that the machine must be able to generate enough force to fracture the specimen.

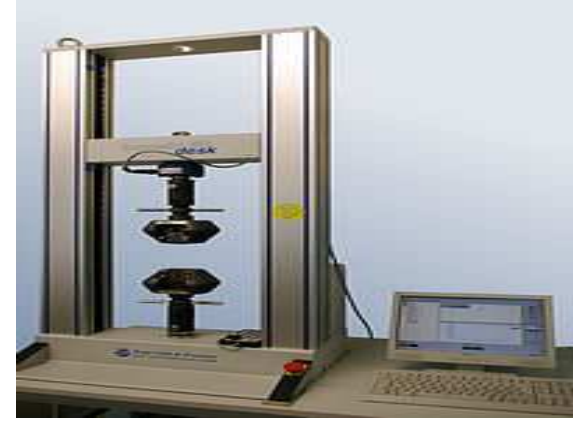

Figure 11: UTM

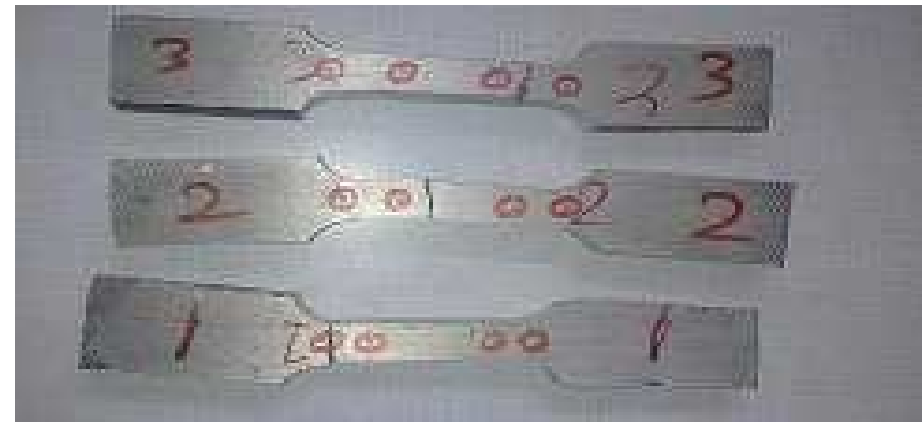

Figure 12: Specimens after Tensile Test

\section{Hardness Test}

Hardness is a measure of how resistant solid matter is to various kinds of permanent shape change when a compressive force is applied. Some materials, such as metal, are harder than others. Macroscopic hardness is generally characterized by strong intermolecular bonds, but the behavior of solid materials under force is complex; therefore, there are different measurements of hardness: scratch hardness, indentation hardness, and rebound hardness.

\section{Impact Test}

In mechanics, an impact is a high force or shock applied over a short time period when two or more bodies collide. Such a force or acceleration usually has a greater effect than a lower force applied over a proportionally longer time period of time. The effect depends critically on the relative velocity of the bodies to one another. 
The Charpy impact test, also known as the Charpy V-notch test, is a standardized high strain-rate test which determines the amount of energy absorbed by a material during fracture. This absorbed energy is a measure of a given material's notch toughness and acts as a tool to study temperature-dependent ductile-brittle transition. Izod impact testing is an ASTM standard method of determining the impact resistance of materials. An arm held at a specific height (constant potential energy) is released. The arm hits the sample. The specimen either breaks or the weight rests on the specimen. From the energy absorbed by the sample, its impact energy is determined. A notched sample is generally used to determine impact energy and notch sensitivity.

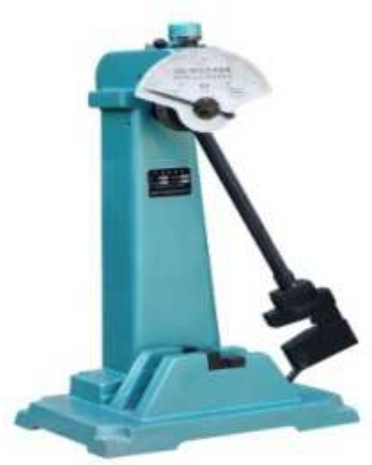

Figure 13: Impact Tester

\section{Microstructure}

The microstructure is the small-scale structure of a material, defined as the structure of a prepared surface of the material as revealed by a microscope above $25 \times$ magnification. The microstructure of a material can strongly influence physical properties such as strength, toughness, ductility, hardness, corrosion resistance, high/low-temperature behavior or wear resistance. These properties, in turn, govern the application of these materials in industrial practice.

\section{Scanning Electron Microscope (SEM)}

A scanning electron microscope (SEM) is a type of electron microscope that produces images of a sample by scanning it with a focused beam of electrons. The electrons interact with atoms in the sample, producing various signals that contain information about the sample's surface topography and composition. The electron beam is generally scanned in a raster scan pattern, and the beam's position is combined with the detected signal to produce an image. SEM can achieve resolution better than 1 nanometer. Specimens can be observed in a high vacuum, in a low vacuum, in wet conditions

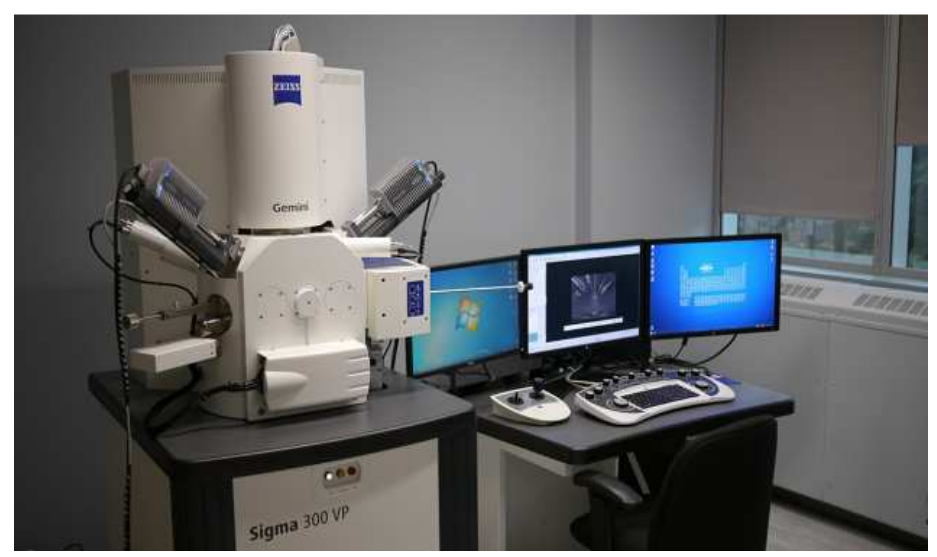

Figure 14: Scanning Electron Microscope 


\section{Test Results}

Test specimen compositions taken in our study are:

Table 3: Composition of Materials in the Specimen

\begin{tabular}{|c|c|c|c|}
\hline Specimen No & $\begin{array}{c}\text { Aluminum } \\
\text { Composition }\end{array}$ & $\begin{array}{c}\text { Copper } \\
\text { Composition }\end{array}$ & $\begin{array}{c}\text { Silicon Carbide } \\
\text { Composition }\end{array}$ \\
\hline 1 & $85 \%$ & $5 \%$ & $10 \%$ \\
\hline 2 & $85 \%$ & $10 \%$ & $5 \%$ \\
\hline 3 & $85 \%$ & $7.5 \%$ & $7.5 \%$ \\
\hline
\end{tabular}

Results obtained after conducting different tests on 3 specimens are:

Table 4: Test Results

\begin{tabular}{|l|c|c|c|}
\hline \multicolumn{1}{|c|}{ Tests } & $\begin{array}{c}\text { Tensile Strength } \\
(\mathbf{M P a})\end{array}$ & $\begin{array}{c}\text { Hardness } \\
\text { (BHN) }\end{array}$ & $\begin{array}{c}\text { Toughness } \\
\text { (Joules) }\end{array}$ \\
\hline Specimen 1 & 92.99 & 68.83 & 4.67 \\
\hline Specimen 2 & 75.53 & 76.97 & 5.33 \\
\hline Specimen 3 & 50.47 & 76.50 & 4.00 \\
\hline Pure Aluminum & 48 & 43 & 3.9 \\
\hline
\end{tabular}

The test results show that the Tensile strength of specimen- 1 is more than specimen- 2 and specimen-3, Hardness and Toughness of specimen-2 are more than specimen -1 and specimen-3.

\section{Microstructures}

Following are the microstructures of Specimen-1, Specimen-2, and Specimen-3.

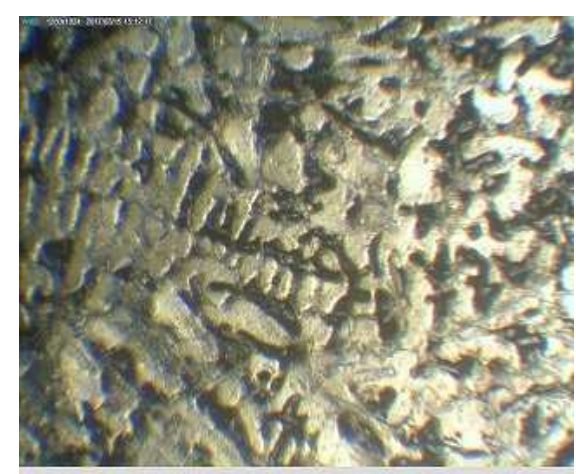

Figure15: Specimen-1

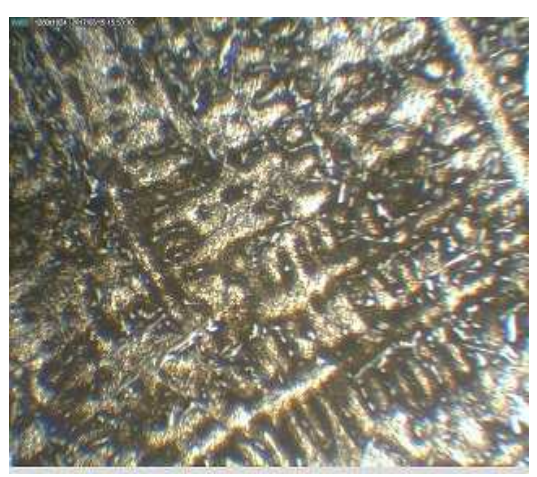

Figure 16: Specimen-2

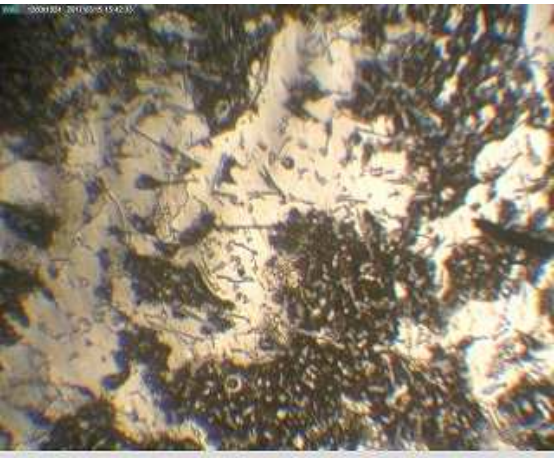

Figure 17: Specimen-3

From the figures of the 3 specimens, it is clear that specimen 3 has small grain size when compared with specimen-1 and specimen-2.

\section{CONCLUSIONS}

Pure aluminum's tensile stress is about 48mpa. Its Brinell hardness number is about 43. Its impact strength is very low, and it is about 3.9Joules. When compared to pure aluminum our composite's Tensile strength is increased by about 1.9 times, Impact strength is increased by about 1.3 times and Hardness is increased about 1.7 times.

So it is obvious that aluminum when used in combination with any other metals which are having good mechanical properties, gives excellent mechanical properties like hardness, tensile stress, impact strength etc. 
The main objective of composites is to obtain better mechanical properties of the composite than the pure aluminum and to provide a balance between mechanics and material science aspects.

This work deals with the fabrication of a new composite material using aluminum as base metal and other two materials such as copper and silicon carbide are additives.

\section{REFERENCES}

1. Revankar, G. (2003). "Introduction to hardness testing." Mechanical testing and evaluation, ASM Online Vol. 8

2. J. Manoj kumar and N. Gopikrishna “ Comparative Studies On Mechanical Characteristics Of Granulated Blast Furnace Slag And Flyash Reinforced Aluminium Composites" International Journal of Mechanical Engineering and Technology (IJMET) Volume 8, Issue 11, November 2017, pp. 277 - 284

3. Czichos, Horst (2006). Springer Handbook of Materials Measurement Methods. Berlin: Springer.

4. Poursartip, A. (1993). Instrumented Impact Testing at High Velocities, Journal of Composites Technology and Research

5. Toropov, AI. (1998). Dynamic Calibration of Impact Test Instruments, Journal of Testing and Evaluation.

6. P. Nagabharam "Fabrication, Characterization And Testing Of Aluminum Based Composite Material” 'International Journal of Mechanical Engineering and Technology (IJMET) Volume 8, Issue 11, November 2017, pp. 494-499

7. Dieter, George E. (1989). Mechanical Metallurgy. SI Metric Adaptation. Maidenhead, UK: McGraw-Hill Education.

8. Wang, H., Li, X. D., Yu, J. S., \& Kim, D. P. (2004). Fabrication and characterization of ordered macroporous PMS-derived SiC from a sacrificial template method. Journal of Materials Chemistry, 14(9), 1383-1386.

9. P. Nagabharam*1, L. Radhakrishna*2, Dheeraj Joshi*3 “Mechanical Properties OF Aluminum Based composite materials" International Journal of Engineering Research | Vol.3., Issue.6., 2015 (Nov.-Dec.,) | pp 242-245 
